\title{
Economic Valuation of the Taj Mahal in India: The Contingent Valuation Method
}

Sri Lanka Journal of Social Sciences and Humanities Volume 1 Issue 1, February 2021: 43-51 ISSN: 2773 692X (Online), 27736911 (Print) Copyright: (C) 2021 The Author(s)

Published by Faculty of Social Sciences and Languages, Sabaragamuwa University of Sri Lanka Website: https://www.sab.ac.lk/sljssh

\author{
Sadia Islam. ${ }^{1, *}$ \\ ${ }^{1}$ Dhaka School of Economics, Dhaka-1000, Bangladesh.
}

Received: 10 November, 2020, Revised: 12 January, 2021, Accepted: 29 January, 2021.

How to Cite this Article: Sadia Islam. (2021). Economic valuation of the Taj Mahal in India: The contingent valuation method. Sri Lanka Journal of Social Sciences and Humanities, 1(1), 43-51.

\begin{abstract}
India has a lot of historical places. Among them one of the most precious is the Taj Mahal. Due to fewer threats to conservation, Taj is placed on the1996 watch list of the 100 most endangered sites by the World Monument Fund. In this study, an attempt was made to calculate the economic value of Taj Mahal in India in relation to the conservation issues. This study assesses households' WTP for Taj Mahal conservation through a CVM study. Single Bounded Dichotomous Choice with an open-ended format was used to elicit households' willingness to pay from 200 households. Out of 200 sample respondents, 70.50 percent were found to be willing to pay the proposed bid prices for Taj Mahal conservation, whereas the remaining 29.50 percent rejected the proposed bid prices. Logit model was employed to assess the determinate of willingness to pay and probit model was also applied to estimate mean willingness to pay (WTP), and the study shows that the mean willingness to pay estimated from the Single Bounded Dichotomous Choice model was Rs. 109.92(US\$1.50)per month per household. The results of the study have found the socioeconomic and demographic characteristics; awareness and attitude of the households are responsible for households WTP for Taj conservation. Therefore, policy and program intervention designed to address the issue of conserving the Taj Mahal in India needs to take into account these factors to make it more effective.
\end{abstract}

Keywords: Conservation, Contingent Valuation Method, Economic Valuation, Historical Place, Willingness to pay

\section{INTRODUCTION}

The historical monument is a matter of pride for any country. It presents countries' culture and traditional identity. Every country has its own historical monument which is treated as a valuable asset for that country. Historical creation or places are not only related to the culture but also it is considered an important element for economic development (Safiullin et al., 2015). India is a country that has plenty of several historical sites but having historical places is also invoked for the conservation and better management of these places. Several famous historical sites are now in danger due to environmental pollution (air, water), natural disasters (floods, precipitation, earthquakes, landscapes) different human activities (farming, irrigation, unplanned industrialization, constructions), etc. To solve this problem not only the government initiative but also individual awareness is essential. Also, people's active participation and contribution to the conservation of the historical monument has been strongly taught as an unplanned management technique all over the world.

The main aim of this study was to find out the economic benefits of historical monuments to find out their economic value in relation to conservation issues. The work focuses on a very special historical monument and one of the seven wonders of this world. Taking into account its historical significance and tourism value this study finds an economic (conservation) value of this site using a contingent valuation method.

Taj Mahal was created by the Mughal emperor Shah Jahan in 1632 as a grave of his beloved wife, Mumtaz Mahal. Later it was also used as the tomb of Emperor Shah Jahan (Pandey.
G., 2014). Taj Mahal was denominated as a UNESCO world heritage site in the year 1983 for being one of the universally extolled precious arts of India. Moreover, the Taj Mahal, which is the symbol of India's rich history, was announced as a winner of the new Seven Wonders of the World (20002007) initiative. But unfortunately, this iconic monument is now in danger due to dug poop and industrial pollution. The fabulous white marbles have turned into green, black, brown, and yellow. Moreover, cracks have been found at different places in the marble slabs. This is to attract different International Media like the Art Newspaper; BBC etc. published different reports on this issue.Primarily this problem relates to the establishment of nearby industries and oil refineries.After that, the government of India appointed a scientific expert committee to find out the real scenario.The finding of this expert group represents that atmospheric pollution plays a minimal role and their different other factors are responsible for the changes in Taj Mahal (Agrawal. O.P., 2014). After that the Times of India reported that the government is preparing a 100-year plan for the Taj Mahal conservation. The plan includes stopping industries near Taj, impeding pollution discharge into the Yamuna River, and also cleaning up this river (Dash and Mohan, 2018). This plan also mentioned a rubber dam, which will be set up downstream of Taj and introducing a green mass transport system for Agra and so on. Further, there is a need to involve an international expert to make a complete conservation plan of the Taj Mahal.

The Taj Mahal is considered as a symbol of love, but due to different conservation threats the Taj Mahal is mentioned in the 1996 watch list of the 100 most endangered sites by the

*Corresponding author: Tel.: +8801673105235; Email: sadia_manoar@yahoo.com

https://orcid.org/0000-0002-9380-3376 
world monuments fund world monument fund 1996 and still, it is listed as an endangered monument (World Monuments Fund, 1996). Moreover, not only in terms of the cultural or historical but also this monument have a high economic significance for the Indian economy. According to the Indian statistical data in the FY 2019, the Taj Mahal was the highest visited ticketed monument by domestic visitors at nearly 5.6 million (Keelery. S.,2020). To highlight the economic importance of the Taj it is also mentionable that revenue earned by the Taj Mahal was 77 crores. According to the Lok Sabha data total annual average revenue generated from the monument in the last three years is nearly 61.4 crores. Therefore, the conservation of the Taj Mahal is a very essential issue for Indian cultural and economic perspectives. It has been identified that there is still a knowledge gap on Taj Mahal conservation issues.The main goal of this study is to estimate the economic value of the Taj Mahal related to the conservation issue in India to help formulate a long-term policy of conservation program.

\section{LITERATURE REVIEW}

Conservation of endangered monuments is a matter of value. Several techniques exist to measure the economic value placed by people on conserving historical sites. These include the hedonic pricing approach (HPA), the travel cost method (TCM), and the contingent valuation method (CVM) (Carson et al., 1996). The CVM is one of the best techniques to measure such values by using survey questions to elicit people's started preference for public goods, such as the preservation of historical sites, wildlife species, and outdoor recreational amenities (Jakobsson \&Dragun, 1996).

Kabir \& Islam (2014) conducted a study to determine the households' willingness to pay as an existing value for the Royal Bengal Tiger conservation in the Sundarbans. They used a contingent valuation survey to find out the households' willingness to pay. They used ten potential explanatory variables in the model. They used the Logit model to assess the determinants of willingness to pay. Findings from the Logit model used to assess determinants of respondents' WTP behaviors revealed that their socio-economic characteristics, awareness, and attitude were the most important determining factors in this regard.

Dutta et al., (2007) conducted a study and find that urban planner in developing countries takes their initiative to reserve heritage sites for getting more visitors attraction. The paper mainly focuses on the very ancient and important historical place the Prinsep Ghat, in India. Thispaper used the stated preference method to identify the total economic value in Prin Sep Ghat in Calcutta, India. This survey strictly follows the NOAA panel guideline, for the interview they followed face to face interview method. This study uses lifetime willingness to pay (LWTP) rather than WTP. This study used the two most important regression models, the TOBIT model, and the truncated model. The finding of the study presents that the huge demand for the site can be used for effective marketing sites without changing its historical identity.

World Bank Group (1998) conducted a CVM survey of the urban World Heritage site in Morocco. The survey created a hypothetical situation that the government and experts had a plan to preserve the Fes medina historical site. They interviewed a total of 600 visitors to Morocco. They chose randomly the respondent and asked about WTP for the preservation fee. The finding showed that the average WTP among visitors and non-visitors to Fes is $\$ 2.15$ among European households of the preservation of the Fes Medina.

Chambers et al., (1998) conducted a study about the preservation of a historic school building. This work reports on a mailed survey using the payment format. Among the respondents, 151 residents were from urban St. Louis and 154 residents of rural Warrensburg, Mo. They found a mean WTP of $\$ 6$ and total value excess of $\$ 500000$ about ten times the market value of the site.

Garrod et al., (1996) completed a survey about the nonpriced benefits of renovating historic buildings of Newcastle's Grainger Town. It mainly reports of an interview survey of 202 Newcastle taxpayers. They asked the taxpayers whether respondents were willing to pay extra tax for restoring historical buildings. They were also asked an openended WTP question. They estimate a median WTP of $\$ 10.00$. They also asked respondents to collect more spending on different areas within Grainger Town. Respondents show more interest in more areas.

Powe et al., (1996) undertook a study on the benefits received by visitors to heritage sites in Warkworth Castle. The authors wanted to measure the use benefits received by visitors and their conservation values. They choose 201 respondents as their sample size and asked about their WTP to enter the heritage site. The result shows that all visitors mean WTP is $\$ 2.53$ and median WTP $\$ 2.34$. Over 90percent of the respondents thought that some of their admission fees were paid for the preservation of the site when asked that none of the fees were to be used for preservation, mean and median WTP for all respondents dropped to $\$ 1.62$ and $\$ 1.50$ respectively.

Beltra et al., (1996) conducted a study using CVM interviews at three archeological sites in Mexico and seven Mexican cities. They asked the respondent to get two WTP values one for visiting Mexican archaeological sites and another for a monthly contribution to preserving sites. Three sample sizes were 900 respondents for all three sites and for each site 300 respondents were interviewed and 5603 respondents in cities around Mexico. Over 60percent of the observation was dropped because they do not claim to have visited a site in the past year. The mean WTP for the preservation of the seven cities from 3.43 to 16.5 and WTP for preservation ranged among the site from 8.4 to 24.4 new pesos.

Grosclaude et al., (1994) conducted a study to find the value of damage to 16 historical buildings in Nevehatel, Switzerland. This study used CVM to find out the value. The survey asked WTP questions for contributing annually to a fund to maintain the buildings, among the 200 residents. Then they asked an open-ended question to know about the annual the WTP of the respondent for maintaining the buildings. Among the 200 respondents, only 22 respondents were not agreeing to pay. The mean WTP was 14.3 and the median WTP was 5.0 Swiss Francs but when the indifferent respondents have dropped the amount Increase to 16.0 and 7.5 respectively. The result shows that the average damage per building per year was 283000 Swiss France.

Navrud et al., (1992) did a study to find out the preservation value of the Nidaros cathedral in Trondheim, Norway. They asked 163 Norwegian and foreigners who were visiting the cathedral to find their WTP for the preservation of the responding original parts of the cathedral. Almost two-thirds of the visitors do not exhibit a positive WTP for preserving original paths rather than simply restoring the building. The survey asked a subsample for WTP values for preserving all historical buildings in Norway. No significant difference was 
found between these two samples. WTP for all historical buildings in Norway was higher than for only the cathedral.

\section{Observations and research gaps}

Observations and research gaps identified from the review

- The Taj Mahal is the 100 most endangered sites (WMF, 1996) and under threat to many sources;

- Economic valuation is the most effective tool for valuation of the endangered monuments;

- CVM is a highly applied and more reliable monetary evaluation method for measuring the economic value of the endangered historical monument like the Taj Mahal;

- It can be argued that more than 70 percent of the study, which used CVM is followed the dichotomous-choice method to ask the WTP question;

- A Large number of the study follows the openended question format and few studies follow payment card question format; and

- There is a knowledge gap on the Taj Mahal economic value-no study has been conducted in connection with the economic value related to conservation using CVM.

\section{MATERIALS AND METHODS}

This study explores how the households of Agra City value the conservation of the historic site, Taj Mahal, which can be used to ensure the sustainable management of the most iconic historical sites.

\section{Research Design}

The study undertook an exploratory cross-sectional survey. Households were selected using simple random sampling to avoid selection bias.

\section{Sample, Sampling Technique, and Data Sources}

The sample has been selected from residents of Agra city. The city is chosen based on the fact that the Taj Mahal is situated in Agra and hence more people may be shown their interest to preserve the Taj Mahal. Azizpur area of Agra city was randomly selected. There are 1727 households in the study area Azizpur of Agra. For selecting residents for the survey of the Azizpur area, again a simple random sampling technique has been employed. A total of 200 households wereused for the analysis. The respondents were generally above 18 years old who are well known about family expenditures and income. A hypothetical market scenario was developed to assess the city residents' willingness to pay (WTP) for the conservation of the Taj Mahal. The respondents were presented with the latest information about the present condition, the polity, and institutional issues that need to be addressed in conserving the Taj Mahal in India.

\section{Method of Data Collection}

Primary data were collected from sample respondents through a structured questionnaire via face to face interview as suggested for the CV survey. Data on social, demographic, institutional, economic, awareness, and willingness to pay for the Taj Mahal conservation were collected through this survey. This study employs the Single Bounded Dichotomous (SBD) choice format with an open-ended follow-up question to elicit respondents' WTP as an economic value for Taj Mahal conservation in the study area.

Designing the Questionnaire and Administering the Interview
According to Mitchell and Carson (1989), the questionnaire was divided into three parts. The first part of the survey questionnaire discussed some socio-economic variables of the selected households. The socio-economic information part includes questions about age, education, income, number of family members, etc. The second part of the questionnaire presents respondents' cultural awareness, attitude, and knowledge towards the Taj Mahal conservation. The last part of the questionnaire presents a detailed description of the Taj Mahal conservation to be undertaken.

In line with Then the dichotomous choice elicitation format a respondent was asked about his/her WTP to assess the existence value of conserving the Taj Mahal. From the six alternative bid values, one bid value was randomly assigned to each respondent. After that, this survey asked an openended follow-up valuation question and the reasons for inconsistencies if any. At the end of the respondents who refused the bid value offered in the survey were asked the reason why they were not willing to pay for the conservation of the Taj Mahal in India.

\section{Designing the Bid Values}

Bid design is important from the point of view of the efficiency of the estimators because they determine the variance-covariance matrix when they are the only repressor. For this reason, in this study before the final survey was implemented a pilot survey was conducted to come up with starting bid values. A total of 30 households were selected for the pilot survey purpose. The main objective of the pilot survey was to elicit the payment vehicles and to set up bid prices. This study used six alternative bid values to elicit household's willingness to pay as a support Taj Mahal conservation practices which were $10,20,50,80,100$, and 200 Rs. An increase in bid value may have a negative impact on the household's willingness to pay support of Taj Mahal conservation practices if it is considered as a normal good.

\section{Methods of Data Analysis}

The data collected from the CV study will analyze in two ways

\section{- Using descriptive statistics and}

- Using economic model

Logit and Pobit were used in this study. A logit model will be applied to the respondent's response to the WTP elicitation question. On the other hand, the purpose of the Pobit model is to estimate mean WTP for the closed-ended format as stated by Haneman et al. (1991). Sophisticated statistical data analysis software, STATA, and SPSS was used for analyzing the collected data.

\section{Theoretical Framework}

In the dichotomous choice method, individuals are assumed to have utility function, $U$, income $(I)$, and a set of conditioning factors $(S)$

$\mathbf{U}(\mathbf{l} ; \mathbf{S})$

With the conservation of the Taj Mahal, each individual is confronted with a specified bid value, BID, which she/he could contribute towards the conservation initiative. It is assumed that the individual would accept a suggested BID to maximize his or her utility under the following conditions and reject it otherwise (Hanemann, 1984):

$\mathbf{U}\left(\mathbf{1}, \mathrm{I}\right.$-BID; S) $+\varepsilon_{1} \geq \mathbf{U}(\mathbf{0}, \mathrm{I} ; \mathbf{S})+\varepsilon_{0}$

Here, $\varepsilon_{1}$ and $\varepsilon_{0}$ are independently distributed random variables with zero means. Therefore, the probability that a household will decide to pay for the conservation of the Taj Mahal is the probability that the conditional indirect utility 
function for the proposed intervention is greater than the conditional indirect utility function for the status quo. Our dependent variable is dichotomous and equals 1 if the household is willing to pay a bid amount as economic value to the conservation of the Taj Mahal, and 0 otherwise.

The general form of the estimation form is:

The general form of the estimation form is:

$\boldsymbol{Y}_{i}^{*}=\boldsymbol{X}_{\boldsymbol{i}} \boldsymbol{\beta}^{\prime}+\varepsilon$

Where,

$Y_{i}=$ Is the dependent variable

$X_{i}=$ Is a vector of independent variables

$\beta^{\prime}=$ is a vector of parameters to be estimated and

$\varepsilon=$ is the error term

In practice, $Y_{i}^{*}$ is unobservable. What we observe is a dummy variable $Y_{i}$ defined by

$Y_{i}$

$=\left\{\begin{array}{c}1 \text { if } Y_{i}^{*}>0 \text { or } U(1, I-B I D ; S)+\varepsilon_{0} \geq U(0, I: S)+\varepsilon_{1} \\ \text { 0otherwise }\end{array}\right.$

The probability that a household is willing to pay to for the conservation of the Taj Mahal is:

$$
\begin{aligned}
& \operatorname{Prob}(Y=1 \mid X)=\operatorname{Prob}\left(Y^{*}>0\right) \\
& =\operatorname{Prob}\left(X_{i} B^{\prime}+\varepsilon>0 \mid X\right) \\
& =\operatorname{Prob}\left(\varepsilon>-X_{i} B^{\prime} \mid X\right)
\end{aligned}
$$

If the distribution is symmetric,

$$
\begin{aligned}
& \operatorname{Prob}(Y=1 \mid X)=\operatorname{Prob}\left(\epsilon<X_{i} B^{\prime} \mid X\right) \\
& =\left(\boldsymbol{X}_{\boldsymbol{i}}, \boldsymbol{B}^{\prime}\right)
\end{aligned}
$$

Where $\mathrm{F}$ is a cumulative distribution function (cdf).

\section{Empirical Model Specification}

\section{Estimating Factors Affecting Willingness to Pay}

By choosing the logistic cdf in equation (2) for the logit model, the probability that the $i^{\text {th }}$ household is willing to pay for the maintenance of the Taj Mahal is:

$$
\operatorname{Prob}(Y=1 \mid X)=F\left(X_{i}, B^{\prime}\right)=P_{i}=\frac{e^{z_{i}}}{1+e^{z_{i}}}
$$

$Z_{i}$ is a linear function of $\mathrm{n}$ explanatory variables $\left(X_{i}\right)$, and expressed as:

$$
\boldsymbol{Z}_{\boldsymbol{i}}=\boldsymbol{\beta}_{\mathbf{0}}+\boldsymbol{X}_{\mathbf{1 i}} \boldsymbol{\beta}_{\mathbf{1}}+\boldsymbol{X}_{\mathbf{2 i}} \boldsymbol{\beta}_{\mathbf{2}}+\boldsymbol{X}_{\mathbf{3 i}} \boldsymbol{\beta}_{\mathbf{3}}+\cdots+\boldsymbol{X}_{\boldsymbol{n}} \boldsymbol{\beta}_{\boldsymbol{n}}
$$

If $P_{i}$ is the probability that the ith household is willing to pay for the conservation of the Taj Mahal, then $\left(1-P_{i}\right)$, the probability of not willing to pay, is

So, we can write

$$
1-P_{i}=\frac{1}{1+e^{z_{i}}}
$$

$$
\frac{P_{i}}{1-P_{i}}=\frac{1+e^{z_{i}}}{1+e^{-z_{i}}}=e^{Z_{i}}
$$

Where $P_{i} /\left(1-P_{i}\right)$ is the odds ratio or the ratio of the probability that a household is willing to pay for the conservation of the Taj Mahal to the probability that a household is not.

Taking the natural logarithm, we get the log of the odds ratio, which is known as the logit model:

$L_{i}=\ln \left(\frac{P_{i}}{1-P_{i}}\right)=\ln \left(e^{Z_{i}}\right)=Z_{i}$

If the error term $(\varepsilon)$ is taken into account the logit model becomes:

$Z_{i}=\beta_{0}+X_{1 i} \beta_{1}+X_{2 i} \beta_{2}+X_{3 i} \beta_{3}+\cdots+X_{n i} \beta_{n}+$ $\varepsilon \ldots . . . . . . . . . . . . . . . . .(5)$

Where $B_{0}$ is an intercept which tells us the log-odds in favor of paying for the conservation of the Taj Mahal when the coefficients of all included explanatory variable are assumed to be zero. $\beta_{1 \rightarrow k}$, are slope parameters to be estimated in the model, respectively. The slope tells how the log-odds in favor of paying for the conservation of Taj Mahal change as each independent variable changes. $Z_{i}$ is also referred to as the log of the odds ratio in favor of paying for the conservation of the Taj Mahal above econometric model (equation 5) is used to identify factors affecting the WTP of a household by using the iterative maximum likelihood estimation procedure. To test the reliability and overall fitness of the discrete choice model, we also have applied the likelihood ratio chisquare test (Mukherjee, et al., 1998).

\section{WTP Sensitivity Test Equations}

For the derivative approach (marginal effect)

$$
\begin{gathered}
\frac{\delta \operatorname{Prob}(Y=1 \mid X)}{\delta X_{k}}=\left[\frac{1}{1+e^{Z_{i}}}\right]\left[1-\frac{1}{1+e^{Z_{i}}}\right] \beta_{k} \\
=P_{i}\left(1-P_{i}\right) \beta_{k} \ldots \ldots \ldots \ldots \text { (6) }
\end{gathered}
$$

This calculation is applied when $\delta \mathrm{Xk}$ is small; in other words, this can be applied when we are interested in knowing the elasticity of willingness to pay at a point concerning unit changes in a continuous variable $\delta X_{k}$. For the case of a dummy variable - e.g., a change from 0 to 1 - the formula is:

$\frac{\Delta P_{i}}{\delta X_{P_{i}}}=\operatorname{Prob}\left((Y=1 \mid X),\left(X_{k}=1\right)\right)-\operatorname{Prob}((Y=1 \mid X)$,

$\left.\left(\boldsymbol{X}_{\boldsymbol{k}}=\mathbf{0}\right)\right)$

The above two equations are used to explain how a change in the variable of interest affects willingness to pay for the conservation of the Taj Mahal.

\section{Estimating of the mean and aggregate willingness to pay}

Assuming the error term is distributed with mean zero and variance equal to one, equation (2) takes the form of a probit model. Then, divide the intercept $(\alpha)$ by the coefficient associated with the bid value $(\beta)$. Assuming the probability of a household's willingness to pay for the conservation of the Taj Mahal is a linear function of bid value, the following probit model is specified to calculate the mean WTP:

Then, mean WTP $(\mu)$ using the probit model as follows:

$\boldsymbol{\mu}=\frac{\alpha}{\beta}$

Where, $\alpha$ is the constant term, and $\beta$ is the bid coefficient. Then, the aggregate willingness to pay (AWTP) is obtained by multiplying MWTP by the total households in the study area (TH) measured in Taka; this gives:

\section{$\boldsymbol{A W T P}=\boldsymbol{M W T P} * \mathbf{T H}$ \\ Measurement of Variables and Hypotheses}

The dependent variable in our WTP estimation was households' willingness to pay to support conservation practices for the Taj Mahal is ready to contribute (Willing to pay).

One consideration is whether the variables that influence WTP are policy-relevant, that is, whether WTP can be influenced by various interventions. The explanatory variables have been chosen based on the literature. Kabir and Islam (2014) did work to determine the household's willingness to pay as an existing value for the Royal Bengal Tiger conservation in the Sundarbans. They used a contingent valuation survey to find out people's willingness to pay. They used ten potential explanatory variables in the model. After doing slight modifications a total of tenexplanatory variables have been selected for this study. Thus, the following 10 potential explanatory variables, which are hypothesized to influence households' willingness to pay as the existing value to support the Taj Mahal conservation, were selected. 
Table 1: Description of variables

\begin{tabular}{|c|c|c|c|c|}
\hline & Variables & Description & Type & Expected Sign \\
\hline 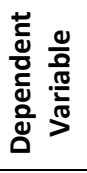 & WTP & Ready to contribute the proposed bid & Dichotomous & \\
\hline \multirow{10}{*}{ 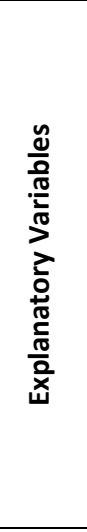 } & AGE & Age of the Household Head & Continuous & $\begin{array}{l}\text { Positive/ Nega- } \\
\text { tive }\end{array}$ \\
\hline & GENDER & Sex of Households & Nominal & Negative \\
\hline & FAMILY & Number of Family Member of Household & Continuous & Negative \\
\hline & EDUCATION & Education Level of the Household Head & Continuous & Positive \\
\hline & INCOME & Total Monthly Income of the Family & Ordinal & Positive \\
\hline & IDENTITY & Important for cultural identity & Dummy & Positive \\
\hline & THREAT & Taj Mahal is under threat & Dummy & Positive \\
\hline & CONSERVATION & $\begin{array}{l}\text { Like to see the Taj Mahal Conservation pro- } \\
\text { gram }\end{array}$ & Dummy & Positive \\
\hline & CITIZEN & $\begin{array}{l}\text { Citizen's involvement important for conser- } \\
\text { vation fund }\end{array}$ & Dummy & Positive \\
\hline & BID & Bid Value & Continuous & Negative \\
\hline
\end{tabular}

Source: Compiled by the author, 2020.

\section{RESULTS AND DISCUSSION}

\section{Descriptive Statistics}

This study analysisanalyses's how much economic value household places on the Taj Mahal conservation and how socioeconomic and demographic factors affect this value. Out of 200 sample respondents, 70.50 percent were found to be willing to pay the proposed bid prices for the Taj Mahal conservation, whereas the remaining 29.50 percent rejected the proposed bid prices. (Table 2). The mean of the bid values for non-willing households are found to be 149.02 with a minimum of 10 and a maximum value of 200 on the other hand, the bid value of disposed households is 38.95 which much lower than the bid offered to the non-willing group. The result shows that the variable is statistically significant at a 1 percent probability level. The maximum willingness to pay for a non-willing household is lower than that of the willing household, which is estimated to be 18.83 and 55.68 taka respectively.

Table2: Household Willingness to Pay, Bid Value, and Maximum Willingness to Pay

\begin{tabular}{|c|c|c|c|c|c|c|c|c|c|}
\hline \multirow{2}{*}{ Variable } & \multirow{2}{*}{$\begin{array}{r}\text { percent for } \\
1 \text { dummy } \\
\text { variable }\end{array}$} & \multirow{2}{*}{$\begin{array}{r}\text { Mean } \\
(n=200)\end{array}$} & \multicolumn{2}{|c|}{ non-willing ( $n=59$ ) } & \multicolumn{4}{|c|}{ Willing ( $n=141$ ) } & \multirow{2}{*}{$\begin{array}{r}\text { Mean Diff } \\
\text { (t-test) }\end{array}$} \\
\hline & & & Mean & $\operatorname{Min}$ & $\operatorname{Max}$ & Mean & Min & Max & \\
\hline WTP & 70.20 & & & & & & & & \\
\hline BID & & 76.33 & 149.02 & 10 & 500 & 38.95 & 10 & 200 & $8.54 * * *$ \\
\hline MWTP & & 37.49 & 18.83 & 0 & 200 & 55.68 & 10 & 100 & \\
\hline
\end{tabular}

*** Statistically significant at 1 percent

Source: Compiled from the Primary Survey, 2020.

Above presents the distribution of "yes" and "no" responses along the bid prices explain argument and hypothesis that states the probability of 'yes' responses decline with higher bid values. It also explores the relationship between bid values to average maximum willingness to pay to support Taj Mahal conservation in India.

Table 3 shows the sex composition of sample households from the total sample size of 200 , out of which only 30 or 15.00 percent of the respondents were found to be femaleTable 3: Sex Composition of the Sample Households

headed households and the remaining 170 or 85.00 percent were male-headed households. Out of the total sample households taken, 141 (70.50 percent) were willing to take part in the conservation process and contribute the randomly offered bids and the other 59 (29.50 percent) of the households were not willing to pay. Out of all the 59 nonwilling households, female-headed households contribute 59.32 percent while male-headed households were the other 40.67 percent.

\section{Willing to pay existence value for the conservation of Taj Mahal}

\begin{tabular}{lrrrrrrr}
\hline & \multicolumn{2}{c}{ Not Willing } & \multicolumn{2}{c}{ Willing } & \multicolumn{2}{c}{ Total } \\
Sex & No & Percentage & No & Percentage & No & Percentage & $\chi 2$ \\
\hline Female & 35 & 59.32 & 51 & 36.17 & 86 & 41.50 & .13 \\
Male & 24 & 40.67 & 90 & 63.82 & 114 & 62.50 & \\
Total & 59 & 100 & 141 & 100 & 200 & 100 \\
\hline
\end{tabular}

Source: Compiled from the Primary Survey, 2020. 
On the other hand, the total 141 willing households, 51.00 (36.17) percent were female-headed and the rest 90 (63.82 percent) were male-headed households. Table 3 indicates that there is no significant relationship between the sex of the household head and willingness status to accept the offered bid. This table presents that, sex difference is not an important component in WTP decision but male-headed households are more ready to pay for conservation of the Taj.

Table 4 shows the relationship of willingness to pay and age, education, number of family members, and income of households in the study area. The average age of the household heads of the respondents was estimated to be 40.02 years with a minimum of 24 and a maximum of 72 years. The willing households had a sample mean age of 39.25 years, while the counterfactual had a sample mean of 38.22 years. There is no significant difference between the non-willing and willing households of different age groups. This underlines that age difference is not an important component in WTP decision.

The sample households had a total of 200 family members with a minimum of 3 and a maximum of 11 members. The mean household sizes of the non-willing and willing households were 5.33 and 4.53 , respectively, and this difference is statistically significant at 1 per cent probability level; showing that there was a significant difference between the nonwilling and willing households in their family sizes. This is might be the higher number of family members requires more amounts of money as living expenses and fewer surpluses are available to make such voluntary payments as like Taj Mahal conservation.

The mean of the number of years that the household head spent on the school was also computed and the result represents that the mean of years that the sampled household heads spent in school for the willing and non-willing households is 15.37 and 12.96 years, respectively. The total sample means education level of the sampled household was 16.01 years. Similar to family size, the mean education level of the household heads of the willing and non-willing groups had a statistically significant difference at 1 per cent probability level. The significance of the variable indicates the importance of education in influencing household willingness to pay for the conservation of the Taj Mahal.

Table 4: Age, Education, Number of Family Members and Income of the Households

\begin{tabular}{lcccrrr}
\hline \multicolumn{7}{c}{ Willing to pay for the conservation of the Taj Mahal } \\
\hline & Not Willing (N=59) & \multicolumn{7}{c}{ Willing(N=141) } & & \\
Variable & Mean & St.Err & Mean & St.Err & t test & $\begin{array}{r}\text { Mean } \\
(\mathrm{N}=200)\end{array}$ \\
\hline AGE & 38.22 & 1.27 & 39.25 & .855 & 0.16 & 40.02 \\
EDUCATION & 12.96 & .490 & 15.37 & .309 & $-4.78^{* * *}$ & 16.01 \\
FAMILY & 5.33 & .132 & 4.53 & .068 & $4.69^{* * *}$ & 4.65 \\
INCOME & 7.30 & .181 & 5.55 & .129 & $0.30^{* * *}$ & 5.38 \\
\hline
\end{tabular}

*** statistically significant at 1percent

Source: Compiled from the Primary Survey

Table 4shows that there is no statistically significant difference between the two groups in terms of total income at less than 1 percent probability level. Monthly family incomes (from all sources) of the household head were divided into ten different groups in the survey questionnaire. Among them, it is found those respondents, who are willing to pay for the Taj Mahal conservation belonging to the lower-income group (Rs. 30,000-40,000) than the respondents who are not willing to pay for the Taj Mahal conservation. The average respondents who are not willing to pay for the Taj Mahal conservation were in the higher income group
(Rs. 50,000-75,000). Thus, income plays a very less important role in the WTP decision of the residents of Agra city. Table 5shows the relationship of willingness to pay and respondent awareness and thought about cultural importance. 90 percent of the respondents perceived that the Taj Mahal is important for cultural identity and the respondents who were willing to contribute the offered bids in Taj Mahal conservation are found to be as high as 99 percent. Table 5 also shows that 82 percent of households considered that the Taj Mahal is under threat and 18 percent were not in the same thinking.

Table 5: Important for cultural identity, under threat for any source, conservation program, and citizen' involvement to the Taj Mahal conservation fund.

\begin{tabular}{|c|c|c|c|c|c|c|}
\hline \multicolumn{7}{|c|}{ Ready to contribute to the conservation } \\
\hline & \multicolumn{2}{|c|}{ Non-Willing ( $\mathrm{N}=59$ ) } & \multicolumn{2}{|c|}{ Willing ( $N=141)$} & \multirow[b]{2}{*}{$t$ test } & \multirow[b]{2}{*}{$\begin{array}{r}\text { Mean } \\
(\mathrm{N}=200)\end{array}$} \\
\hline Variable & Mean & St.Err & Mean & St.Err & & \\
\hline IDENTITY & .58 & .04 & .99 & .007 & $-4.56 * * *$ & .90 \\
\hline THREAT & .70 & .05 & .95 & .02 & $-4.27 * * *$ & .82 \\
\hline CONSERVATION & .67 & .05 & .96 & .01 & $-5.25 * * *$ & .89 \\
\hline CITIZEN & .59 & .05 & .94 & .01 & $-7.29 * * *$ & .82 \\
\hline
\end{tabular}

*** Statistically significant at 1 per cent Source: Compiled from the Primary Survey, 2020 
Moreover, 89 percent of the respondents likes to see the conservation of the Taj Mahal and 12 percent thought otherwise. The result also presents that the variable Conservation (Like to see Taj Mahal conservation) is statistically significant at 1per cent probability level.

This table also presents that 82 percent of households considered that citizen involvement is important for running the Taj Mahal conservation program and 18 percent were not in the same thinking. The result shows that there is a statistically significant relationship among willingness status importance of the Taj Mahal, Taj is under threat, like to see Taj conservation and perception on the citizen involvement are important for running Taj Mahal conservation program at 1 per cent probability level; showing that these all of the four

Table 6: Logit Model Estimates of WTP

\begin{tabular}{|c|c|c|c|}
\hline Rtc & Coef. & Std. Err. & $P>|z|$ \\
\hline Family & $-0.577^{* * *}$ & 0.331 & 0.01 \\
\hline Education & $0.131^{* *}$ & 0.046 & 0.03 \\
\hline Identity & $3.420 * * *$ & 1.759 & 0.00 \\
\hline Threat & 0.727 & 0.547 & 0.59 \\
\hline Conservation & $0.113^{* *}$ & 0.054 & 0.03 \\
\hline Citizen & $3.340 * * *$ & 1.161 & 0.00 \\
\hline Bid & $-0.036 * * *$ & 0.005 & 0.00 \\
\hline cons & -0.101 & & 0.95 \\
\hline Observations & 200 & & \\
\hline Log-likelihood & -64.033579 & & \\
\hline LR chi2(7) & 134.26 & & \\
\hline Pseudo R2 & 0.5087 & & \\
\hline Prob > chi2 & 0.000 & & \\
\hline
\end{tabular}

*** and $* *$ statistically significant at 1 percent and 5 percent respectively

Source: Compiled from the Primary Survey, 2020

People's perception of the Importance of Taj Mahal conservation has an expected positive effect related to the likelihood of saying "Yes" to the offered bid. Households with higher family sizes are expected to pay less than those who have a smaller family size. This is precise because payment to Taj Mahal conservation largely depends on household expenditure and surplus money. Hence, households with small family sizes may tend to pay more for conservation. The negative sign implies that an increase in household family size decreases the probability of a respondent to support the proposed voluntary contributions to the Taj Mahal at a 1 percent significant level.

The coefficient of this education variable was significant at a 5 percent probability level, which shows that an increase in the household head about the importance of the conservation of Taj Mahal increases its WTP. Education is considered as a measure of cultural awareness and considered that more educated people are having more consciousness for the Taj Mahal conservation which makes WTP more feasible.

Taj Mahal is important for cultural identity (identity) variable has an expected positive effect related to the likelihood of saying "yes" to the offered bid. The coefficient of this variable was found to be significant at a 1 percent probability level which shows that households who consider the Taj Mahal is important for cultural identity to have a higher probability to pay for the conservation of the Taj Mahal. variables are important for running Taj Mahal conservation program increases respondents willingness to pay.

A total of 10 explanatory variables were considered in the econometric model used in this case, out of which only 7 variables were found to be significantly influencing the probability of willingness to pay among the selected households.

\section{Analysis of the Determinants of Households Willing- ness to pay}

Table 6 indicated that the logit estimate, out of total 7 significant explanatory variables hypothesized 4 explanatory variables have positive and significant effects on the probability of respondents accepting the offered initial bid and 2 have a negative and significant effect on the other hand, the rest only 1 explanatory variable were found to be not significant at 5 percent probability level.
The conservation variable has an expected positive effect related to the likelihood of saying "yes" to the offered bid. The coefficient of this variable was found to be significant at a 5 percent probability level which shows that households who like to see the Taj Mahal conservation program have a higher probability to pay for the conservation of the Taj Mahal.

The citizen variable has an expected positive effect related to the likelihood of saying "yes" to the offered bid. The coefficient of this variable was found to be significant at a 5 percent probability level which shows that households who consider citizens' involvement is important for the conservation program to have a higher probability to pay for the conservation of the Taj Mahal. This is because people who consider that citizen involvement is important for the Taj Mahal conservation program to have higher cultural awareness.

The initial bid offered is negative and significantly related at a 5 percent significance level with a willingness to pay for the conservation of the Taj Mahal. This implies the probability of a 'yes' response to the bid increases with a decrease in the offered bid which indicates that the likelihood of accepting an offered bid amount increases as the bid amount goes down and vice versa which is consistent with the economic theory. In general, in the logit model, it is considered that the Taj Mahal is under threat (Threat) variable has expected sigh, but it is statistically not significant. 
Table 7: Marginal Effects of the Explanatory Variables

\begin{tabular}{|c|c|c|c|c|}
\hline Variable & $d y / d x$ & Std.Err. & $\mathbf{z}$ & $P>z$ \\
\hline family & $-0.113 * * *$ & 0.050 & -2.86 & 0.00 \\
\hline education & $0.161^{* *}$ & 0.013 & 2.16 & 0.03 \\
\hline 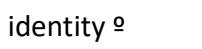 & $0.673 * * *$ & 0.113 & 5.95 & 0.00 \\
\hline threat o & 0.196 & 0.209 & 0.7 & 0.48 \\
\hline 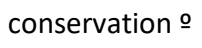 & $0.401 * *$ & 0.209 & -0.97 & 0.33 \\
\hline 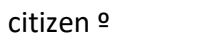 & $0.564 * * *$ & 0.113 & 5.95 & 0.00 \\
\hline bid & $-0.005 * * *$ & 0.001 & -4.59 & 0.00 \\
\hline
\end{tabular}

$* * *$ and ${ }^{* *}$ statistically significant at 1 per cent and 5 per cent respectively Source: Compiled from the Primary Survey, 2020

() $\mathrm{dy} / \mathrm{dx}$ is for discrete change of dummy variable from 0 to 1

The result in Table 7show that keeping the effect of the other factors constant at their mean value, a one-person increase in the total family size decreases the probability of willingness to pay by 11.3 percent. This is because households with higher family size need more money for the household expenses. Hence they are willing to pay less of the existing value in this conservation initiative. The marginal effect estimates of the logit model showed the education level of the household for each additional increment of education from one year level to another. The probability of the willingness by the household to pay for the Taj Mahal conservation will increase by 16.1 percent at less than 5 percent probability level one possible reason could be the respondent with higher income might have a higher perception of historical resource conservation that influences the decision to participate in the Taj Mahal conservation.

Taj Mahal is important for cultural identity (identity) variable is statistically significant at 1 percent probability level. Holding another thing constant, the probability of a household willingness for the conservation of the Taj Mahal increased by 67.3 percent for perceived respondents than the other counter factual ones.

Moreover, variable conservation (like to see the Taj Mahal conservation program) is statistically significant at a 5 percent probability level. Similarly, variable citizen (citizen involvement for the Taj Mahal conservation) is statistically significant at 1 percent probability level. Holding another thing constant, the probability of a household willingness for the conservation of the Taj Mahal increased by 56.4 percent for perceived respondents than the other counter factual ones. Consistent with the earlier expectation and established economic theory, the randomly offered bid value (BID) has a Welfare Measure and Aggregation

Table 9: The Aggregate WTP

\begin{tabular}{ccccccc}
\hline $\begin{array}{c}\text { Name of } \\
\text { the Study } \\
\text { Area }\end{array}$ & $\begin{array}{c}\text { Total } \\
\text { Households }\end{array}$ & $\begin{array}{c}\text { Sampled } \\
\text { Households }\end{array}$ & $\begin{array}{c}\text { No. of } \\
\text { Households with } \\
\text { Protest Zero }\end{array}$ & $\begin{array}{c}\text { HHs with } \\
\text { Valid } \\
\text { Responses }\end{array}$ & $\begin{array}{c}\text { Mean WTP from } \\
\text { Probit } \\
\text { (Indian Rs.) }\end{array}$ & $\begin{array}{c}\text { Total WTP } \\
\text { (Indian Rs. In } \\
\text { per month) }\end{array}$ \\
\hline Agra & 1727 & 200 & 18 & 1572 & $109.92($ US\$1.50) & $\begin{array}{c}172794 \\
\text { (US\$2362.87) }\end{array}$ \\
\hline
\end{tabular}

Source: Compiled from the Primary Survey, 2020

Mean was used as a measure of the aggregate economic value of the Taj Mahal conservation in India arising from this study. There are 1727 households in the study area Azizpur of Agra. After deducting the protest zeros 155 the expected total households with valid responses are 1572 households. The total willingness to pay in the whole study area (Azizpur) negative and significant effect on the WTP for the conservation of Taj Mahal at 1per cent level of significance. The marginal effect here indicates that a one taka increase in the contribution of the proposed fund reduces the probability of being willing to pay for the proposed fund by nearly 0.5 percent.

Estimation of the Mean Willingness to pay (MWTP) and Aggregate Benefit from Single Bounded DC Format CV Study

\section{Mean Willingness to pay (MWTP)}

The mean willingness to pay $(\mu)$ was calculated using the formula from the probit model, following Haab and Mconnell (2002), using the following formula:

$$
\begin{aligned}
& \mu=-\alpha / \beta \quad \ldots . . . . . .(1) \\
\text { Where } \quad & \alpha=\text { a coefficient for the constant term } \\
\beta \quad & =\text { a coefficient for the amount of the bid }
\end{aligned}
$$

that the household was asked to pay.

The probit estimates show that the coefficient for the constant term is -.0136024 and the coefficient for the bid is found to be 1.495134 . Thus, the estimated mean willingness to pay (MWTP) from the probit model for the conservation of the Taj Mahal in India is Rs. 109.92(US\$ 1.50) per month.

Table 8: Probit parameter estimates for the conservation of the Taj Mahal

\begin{tabular}{lrr}
\hline Variable & Estimates & Std. Err \\
\hline Bid & -.0136024 & 0.0018234 \\
_cons & 1.495134 & 0.156317 \\
Log-likelihood & -89.023466 & \\
LR chi2(1) & 69.82 & \\
\hline
\end{tabular}

Source: Compiled from the Primary Survey, 2020 is thus simply the multiplication of the respective means and the number of the expected households.

In Table 9 above, the aggregate WTP was calculated by multiplying the mean WTP by the total number of households who are expected to have a valid response in the selected area. Following this, the aggregate WTP for the conservation 
of the Taj Mahal is computed to be Rs. 172794 (US\$2362.87) per month. This shows that there is a high level of willingness to pay for the Taj Mahal conservation initiative if it is taken seriously.

\section{CONCLUSION}

The main objective of this work was to understand how much the residents of Agra City (In this case Azizpur of Agra City) are willing to pay as an economic value for the conservation of the Taj Mahal in India. The study was designed to find out the variables, which determine respondent's willingness to participate in Taj Mahal conservation and find out how each of the selected variables is related to the willingness of the respondents to participate in the Taj Mahal conservation project. Moreover, this study also attempts to estimate the mean willingness to pay to keep in mind its policy relevance. Based on the results from this study, the Government of India can initiate the Taj Mahal conservation project after a proper benefit-cost analysis based on this information to see if the total benefits from the conservation project would outweigh the total costs before charging households. It is said conservation program is implemented; the study findings can serve as a policy input for involving households/ stakeholders in the management process. The aggregate amount is obtained by multiplying the mean WTP by the households with the valid response from Azizpur. The mean WTP from the probit model estimates is Indian Rs. 109.92 (US\$1.50) per month per household. The mean WTP found from this study indicates that government can generate a substantial amount of revenues for designing, evaluating, or managing a Taj Mahal (historical site) conservation project/policy. Finally, this study only analyses the demand side information for the Taj Mahal conservation of India. It is expected that the findings from the present study may serve as a basis for any possible future study on the ancient historical site Taj Mahal and the need for initiating better management of the Taj Mahal.

\section{REFERENCES}

Agrawal, O.P. (2002). Assessing the conservation needs of the Taj Mahal. Journal of Architectural Conservation, 8(3), 73-87.

Beltrán, E., \& Mariano, R., (1996). Diversified funding methods in Mexican archeology. Annals of Tourism Research, 23 (2), 463-478.

Carson, Richard, T., Robert, C.M, Michael, C., Conaway, \& Navrud, S. (1997). Non-Moroccan values for rehabilitating the Fés Medina. World Bank Report.

Chambers, Catherine, M., Paul, E., Chambers, \& Whitehead, J. C. (1998). Contingent valuation of quasi-public goods: validity, reliability, and application to valuing a historic site. Public Finance Review, 26, 137154

Dutta, M., Banerjee, S., \& Husain, Z. (2007). Untapped demand for a heritage: A contingent valuation study of Pin Sep Ghat, Calcutta. Journal of Tourism Management, 28(1), 83-95.

Dash, D.K. \& Mohan, V. (2018). Govt to draw up a 100-year plan for Taj conservation. The Times of India.

Garrod, G.D., Willis, K. G., Bjarnadittir, H., \& Cockbain, P. (1996). The non-priced benefits of renovating historic buildings. Cities, 13(6), 423430.

Grosclaude, Pascal \& Soguel, N. C. (1994). Valuing damage to historic buildings using a contingent market: A case study of road traffic externalities. Journal of Environmental Planning and Management, $37(3), 279-287$.

Hanemann, W.M., Loomis, J., \& Kanninen, B. (1991). Statistical Efficiency of Double Bounded Dichotomous Choice Contingent Valuation. American J. Agric. Econ, 73 (4), 1255-1263.

Hanemann, W.M., (1984). Welfare evaluations in contingent valuation experiments with discrete responses. American J. Agric. Econ. 71 (3), 332-341.
Jakobsson, K. M., Dragun, A.K. (2001). The worth of a possum: valuing species with the contingent valuation method. Environmental and Resource Economics 19, 211-227.

Kabir. M.A.,\& Islam, N.(2014). Determinants of Households' Willingness to Pay as an Existence Value for the Royal Bengal Tiger Conservation in the Sundarbans: A Contingent Valuation Study. International Journal of Development Studies and Research, 3(3), 49-62.

Keelery, S. (2020) https://www.statista.com/statistics/1021991/indianumber-of-domestic-visitors-ticketed-monuments. Retrieved on 5 January 2021.

Mitchell, R. C., \& Carson, R.T. (1989).Using Surveys to Value Public Goods: The Contingent Valuation Method. Resources for the Future, USA.

Mukherjee, C., White, H., \& Wuyts, M., (1998). Econometrics and Data Analysis for Developing Countries. Routledge.

Navrud, \& Ståle, ed. (1992). Pricing the European environment. Oxford University Press.

Powe, N. A., and Willis, K. G. (1996). Benefits received by visitors to heritage sites: A case study of Warkworth Castle. Leisure Studies 15, 259 275.

Pandey, G. (2014).Taj Mahal: Was India's 'monument to love' built out of guilt? BBC News.

Safiullin, L., Bagautdinova, N., \& Safiullin, N. (2015). Historical and cultural heritage and region's economic: case study central and eastern Russia. Social and behavioral sciences, 188, 151-156.

Timothy C. Haab, \& Kenneth E. Mcconnell. (2002). Valuing Environmental and Natural Resources The Econometrics of Non-Market Valuation. Edward Elgar.

World Bank Group. (1998). Valuing the Benefits of Conservation of the Fés Medina. World Bank.

World Monuments Fund. (1996). Watch list of the 100 Most Endangered Sites. Retrieved on 15 February 2020. 
